\title{
Cervical cancer - still a serious problem for public health in Poland. What is needed to solve it?
}

\author{
Małgorzata Stelmach \\ The MSD Foundation for Women's Health, Warsaw, Poland
}

ADDRESS FOR CORRESPONDENCE: Małgorzata Stelmach, The MSD Foundation for Women's Health, 51 Chłodna St., 00-867 Warsaw, Poland, e-mail: m.stelmach@fzk.org.pl

Cervical cancer is still one of main public health issues in Poland. It is the eighth most common female cancer and the second in the group of women aged 20-44 years. In 2016 there were 2622 newly diagnosed patients registered and 1570 cases of death. The mortality rate from cervical cancer in Poland is 5.75/100,000, which is higher than the European average $(3.8 / 100,000)$ [1]. The current prevention model in Poland is based on cytology screening. The population program of prevention and early detection of cervical cancer run in the years 2006-2015 brought an increase in the participation rate in PAP smear tests, to nearly $40 \%$. This was not enough to achieve the goal proposed in the National Health Program, to reduce the number of deaths from cervical cancer to a maximum of 500 cases in 2015. In 2012 Polish Coalition Against Cervical Cancer analysed existing unmet needs and barriers and defined system changes required to solve the problem of cervical cancer in the country in five areas: education, screening, immunisation, financing, and organisation and recommended them to the Ministry of Health; however, very few were implemented, mostly in the area of screening. At the same time, several other countries focused on primary prevention (HPV vaccination) above screening programs. Cervical cancer caused by oncogenic types of HPV is considered as a preventable disease due to the efficacy of HPV immunisation, which has been proven from real world evidence databases in many countries and screening programs. Australia, for example, announced in 2018 the concept of eradication of cervical cancer by 2028. In Poland, the population program based on education and coordination of cervical screening was not relaunched in 2016, negatively influencing the number of women undergoing cytology tests. HPV screening has not been added to the list of reimbursed procedures, and immunisation against HPV is not included in the National Immunisation Program. Regional and local, mostly short-term, immunisation programs have been organised and covered from public funds voluntari- ly by municipalities, reaching only $5-10 \%$ of the eligible population of 12-13-year-old girls each year. There are no local registers to evaluate the efficacy of these interventions. Decision-makers face aggressive campaigns against HPV vaccination from the pro-epidemic/anti-vaccination movement. It seems that in Poland there is a strong need to:

- implement a national education program with careful segmentation of target groups, based on their roles (HCPs, general population), health educational potential, barriers, etc., leveraging existing experience of different stakeholders (good practices like "Choose Life First Step" www. pierwszykrok.edu.pl or "Don't Pay for Mistakes. Better Prevent!" www.zapobiegaj.pl programs),

- relaunch the population screening program with an active invitation system and usage of modern technology, with a focus on high-risk groups, e.g. less educated and socially excluded women,

- introduce HPV population immunisation,

- establish a register for the HPV-immunised population,

- coordinate health campaigns of the Ministry of Health with other organisational activities.

A coordinated multi-pillar approach might be an effective method of significantly decreasing mortality due to cervical cancer in Poland.

Key words: cervical cancer, cytology screening, HPV vaccination.

\section{DISCLOSURE}

The author reports no conflict of interest.

\section{Reference}

1. Bruni L, Albero G, Serrano B, et al. Human Papillomavirus and related diseases in the world. Summary Report 17 June 2019. ICO/IARC Information Centre on HPV and Cancer (HPV Information Centre). Available from: https://www.hpvcentre. net/statistics/reports/XWX.pdf (accessed: 14 May 2019). 